W. Child - "Wittgenstein, Scientism \& Anti-Scientism in the Philosophy of Mind" - in Wittgenstein and Scientism, eds. Jon Beale and Ian James Kidd, London: Routledge, pp. 81-100.

\title{
Wittgenstein, Scientism, and Anti-Scientism in the Philosophy of Mind
}

\author{
William Child
}

In part 1 of this paper, I sketch Wittgenstein's opposition to scientism in general. Part 2 explores his opposition to scientism in philosophy of mind. How must philosophy of mind proceed if it is to avoid the kind of scientism that Wittgenstein complains about? Part 3 examines a central anti-scientistic strand in Wittgenstein's Last Writings on the Philosophy of Psychology, volume II: his treatment of the 'uncertainty' of the relation between 'outer' behaviour and 'inner' experiences and mental states.

\section{Wittgenstein's anti-scientism}

We can distinguish three levels of hostility in Wittgenstein's comments about science and scientism. There is hostility to the scientism that regards science as the only legitimate form of enquiry. There is hostility to the spirit in which contemporary science is conducted, which, Wittgenstein suggests, is the spirit that informs contemporary western civilization as a whole. And, occasionally, there are signs of an attitude that goes further than the antiscientism expressed in these first two forms of hostility: hostility to science itself.

1.i. At the first level, Wittgenstein sees nothing wrong with science or scientific method as such. What he objects to is the tendency - pervasive, he thinks, in modern society - to treat scientific method as the only legitimate method of enquiry and scientific explanation as the only genuine kind of explanation, and thus to overgeneralize scientific thinking to cases that call for something quite different. That is the point expressed in passages like this:

Science: enrichment and impoverishment. One particular method elbows all the others aside. They all seem paltry by comparison, preliminary stages at best. (CV 60) What does Wittgenstein mean by 'science' and 'scientific method'? The governing aim of science, as he understands it, is causal explanation. ' 'The method of science' is 'the method of reducing the explanation of natural phenomena to the smallest possible number of primitive natural laws; and, in mathematics, of unifying the treatment of different topics by using a generalization' (BB 18). So science, as Wittgenstein presents it, is characteristically reductionist: it seeks to explain phenomena of one kind in terms of phenomena of another, more basic, kind. It is characteristically essentialist; it looks for properties that are common to every member of a kind. And science is exact: scientific language is 'a symbolism used in an exact calculus' (BB 25); it 'follow[s] exact rules'. As far as the current comments are concerned Wittgenstein, as I have said, has no objection to scientific thinking, thus understood, in its own domain. The scientism to which he objects comes with the generalization of scientific thinking to every domain, and the assumption that every question calls for a scientific answer.

It might be objected that Wittgenstein's portrayal of science as being characteristically reductionist and essentialist is a misrepresentation. As philosophers of science have consistently stressed, it is highly implausible that science, as it is actually practised, is universally or even typically reductionist or essentialist. ${ }^{2}$ And if Wittgenstein's opposition to scientism depends on a naïve and distorted view of science, doesn't that undermine his critique? We will return to that natural question in $\S 1$.iv below.

In exploring Wittgenstein's position, it is helpful to start with a concrete example of his opposition to the scientistic tendency to take science as a model for all enquiry: his 
W. Child - "Wittgenstein, Scientism \& Anti-Scientism in the Philosophy of Mind" - in Wittgenstein and Scientism, eds. Jon Beale and Ian James Kidd, London: Routledge, pp. 81-100.

critique of the account of magic and ritual given by the anthropologist Sir James George Frazer in The Golden Bough (Frazer, 1994). Frazer’s account, Wittgenstein thinks, actually involves two forms of scientism: there is the scientism of doing anthropology as though it is a science; and there is the scientism of treating magic in early societies as though it is itself a primitive form of science.

Wittgenstein identifies at least two respects in which Frazer pursues anthropology as though it is a kind of science. In the first place, Frazer aims to understand practices or ceremonies by causally explaining them. He thinks we can explain the character of an 18th Century fire-festival, for instance - the fact that the festival is a representation of human sacrifice, and that it is terrible or sinister - by tracing its causal origins to an ancient custom in which people were actually sacrificed. ${ }^{3}$ In the second place, Frazer thinks that anthropology should look for general explanations: he thinks it counts in favour of a putative explanation that it reveals 'a harmony and consistency' (Frazer 1994, 748) in the practices people have pursued at different times and places. Wittgenstein rejects both these ideas. In the first place, anthropological understanding, unlike scientific understanding, does not involve causal explanation; we cannot achieve the kind of understanding we seek in anthropology by tracing a practice to its causal origins. Understanding a practice depends, rather, on achieving a sympathetic understanding of the significance it now has for its participants. In the case of the 18th Century fire-festival, for instance, 'it is clearly the inner nature of the modern practice which itself seems sinister to us' (RFGB, 145). And it is neither necessary nor sufficient for its having that nature, he thinks, that the modern practice should be derived from an earlier practice in which people were actually sacrificed. Similarly, Wittgenstein rejects Frazer's search for general rules in anthropology. He acknowledges that there are similarities between the fire festivals to be found at different times and places. But, he says, 'besides these similarities, what seems to me to be most striking is the dissimilarity of all these rites. It is a multiplicity of faces with common features which continually emerges here and there' (RFGB, 143). And it is a mistake to think that there must be an underlying feature or motive common to every such rite or festival.

The second form of scientism Wittgenstein finds in Frazer is the scientism of treating magic as though it is itself a primitive form of science: a primitive system of beliefs about the causes and effects of natural phenomena, allied to a system of practices that are supposed to control those phenomena. Frazer sees magic, religion, and science as increasingly sophisticated systems for understanding, predicting, and manipulating the natural world. As human beings become more knowledgeable, he writes, 'magic is gradually superseded by religion' which in turn 'is displaced by science' (Frazer 1994, 805). On this view, as Wittgenstein puts it, 'magic is essentially false physics or, as the case may be, false medicine, technology etc.' (RFGB 129). Magical beliefs are false beliefs about the causes of phenomena. And magical practices are underpinned by false beliefs about their instrumental utility: people stab effigies in the belief that doing so will harm the people the effigies represent; they light fires to cure illness by driving out witches; and so on. Against Frazer's view, Wittgenstein argues that magic is not a primitive form of causal understanding at all: it is not a primitive form of science. It is, rather, an autonomous system of beliefs and practices that people engage in for its own sake. To understand those beliefs and practices, we must see the point they have for the participants; and that is best achieved by relating them to similar kinds of non-instrumental action that we engage in ourselves. For instance:

Burning in effigy. Kissing the picture of one's beloved. That is obviously not based on the belief that it will have some specific effect on the object which the picture represents. It aims at satisfaction and achieves it. Or rather: it aims at nothing at all; we just behave this way and then we feel satisfied (RFGB: 123). ${ }^{4}$ 
W. Child - "Wittgenstein, Scientism \& Anti-Scientism in the Philosophy of Mind" - in Wittgenstein and Scientism, eds. Jon Beale and Ian James Kidd, London: Routledge, pp. 81-100.

Similarly, Wittgenstein thinks, it is a mistake to think that the practice of burning a person in effigy must be based on the belief that doing so is a way of causing harm to the person the effigy represents. We should reject the scientistic assumption that every kind of human activity is at root a kind of science.

1.ii The second level of Wittgenstein's hostility is his objection to the spirit of 'the typical western scientist' (CV 7) which, he suggests, is 'the spirit of the main current of European and American civilization' (CV 6):

Our civilization is characterized by the word 'progress'. Progress is its form rather than making progress being one of its features. Typically it constructs. It is occupied with building an ever more complicated structure. And even clarity is sought only as a means to this end, not as an end in itself. For me on the contrary clarity, perspicuity are valuable in themselves.

I am not interested in constructing a building, so much as in having a perspicuous view of the foundations of possible buildings.

So I am not aiming at the same target as the scientists and my way of thinking is different from theirs (CV 7).

One strand in that comment is a line of thought we have already seen in 1.i: the idea that the modern preoccupation with the methods of science blinds us to other values and other kinds of enquiry; and the insistence that we should not allow human enquiry to be dominated by a single spirit. That comes out in Wittgenstein's remark that he is not aiming at the same target as the scientists and that his way of thinking is different from theirs. But Wittgenstein's comment goes further than a simple plea for pluralism; for he actively criticizes the spirit that, he says, informs contemporary western science and civilization. Science, he writes, is driven by a commitment to making progress, to 'onwards movement [and to] building ever larger and more complicated structures' (PR 7). It embodies an endless quest for novelty, 'add[ing] one construction after another, moving on and up, as it were, from one stage to the next' (PR 7). It involves a crude instrumentalism, which values knowledge only as a means to an end. And 'the spirit in which science is carried on nowadays' (CV 5), he complains, is incompatible with a sense of wonder at nature: 'Man has to awaken to wonder ... Science is a way of sending him to sleep again’ (CV 5). As before, Wittgenstein’s hostility is not directed at scientific method or scientific understanding as such. He does not say that it is impossible to pursue scientific investigation in a different spirit from that which currently dominates western science: a spirit that is less instrumentalist, less obsessed with progress, and more consistent with a sense of wonder. And there is, in the current comments, no indication that Wittgenstein would disapprove of a science that was conducted in such a spirit; he is not expressing hostility to empirical investigation per se.

It is debatable whether Wittgenstein is right about the spirit in which 'typical' scientists do in fact proceed. Scientists certainly want to extend our knowledge of the world. In that sense, they are interested in novelty and they aim at making progress. And, since science is an empirical discipline, the spirit that drives it is bound to differ in some respects from the spirit that drives philosophy, or literature, or art, or music. But there are plenty of scientists whose motivation is entirely non-instrumental, who value knowledge as an end in itself, and whose sense of awe and wonder at nature would rival anyone's. And there are plenty of scientists whose work does not rush endlessly onwards, 'add[ing] one construction after another', but who spend a lifetime striving for a fuller, deeper understanding of some particular area of enquiry. However, even if Wittgenstein misjudges the extent of the spirit he identifies, he is surely right that it exists. And he may well be right that it dominates the 
W. Child - "Wittgenstein, Scientism \& Anti-Scientism in the Philosophy of Mind" - in Wittgenstein and Scientism, eds. Jon Beale and Ian James Kidd, London: Routledge, pp. 81-100.

social institution of science, not to mention the social institution of academic enquiry more generally, including academic philosophy. ${ }^{5}$ His hostility to that spirit is very clear.

\section{1.iii Wittgenstein writes:}

It isn't absurd, e.g., to believe that the age of science and technology is the beginning of the end for humanity; that the idea of great progress is a delusion, along with the idea that the truth will ultimately be known; that there is nothing good or desirable about scientific knowledge and that mankind, in seeking it, is falling into a trap. It is by no means obvious that that is not how things are (CV 56).

And, even more dramatically:

the [atom] bomb offers a prospect of the end, the destruction, of an evil - our disgusting soapy water science. And certainly that's not an unpleasant thought (CV 49).

As before, part of the hostility in these comments is directed at the social institution of science and technology as it currently exists, rather than at scientific method or scientific enquiry itself. Hostility to 'our disgusting soapy water science' is compatible with a more positive attitude to some other kind of science. Nonetheless the first remark just quoted, in particular, comes much closer than the other comments we have considered to expressing outright hostility to science as such. And it gives some support to Bernard Williams's observation that 'Wittgenstein's hatred of the cockiness of natural science' is 'not easy ... to distinguish from a hatred of natural science' (Williams 1973, 91). In particular, the idea that there might be nothing at all that is 'good or desirable about scientific knowledge' goes well beyond either of the first two levels of Wittgenstein's hostility. Admittedly, Wittgenstein does not commit himself to this more extreme view; he says only that 'it is by no means obvious' that there is anything good or desirable about scientific knowledge. But he plainly regards it as a real possibility that there is not. And that does suggest a hostility to scientific enquiry and scientific knowledge as such, not simply hostility to the overgeneralization of scientific thinking, to the social institution of science, or to the spirit in which science is currently pursued.

It is important to acknowledge the existence of this third level of hostility in Wittgenstein's comments about science. But, having acknowledged it, the remainder of the paper will focus on the first two levels, which capture the core of his opposition to scientism.

1.iv. Before proceeding, we must return to the question raised in 1.i above: is Wittgenstein's critique of scientism undermined by its apparent dependence on a naïve view of science - in particular, the image of science as reductionist and essentialist? It is true that some of Wittgenstein's comments do portray science in that way. But the force of his case against scientism is largely unaffected by that misrepresentation.

First, the central core of his anti-scientism is his opposition to the imperialism of science: to our tendency to treat scientific enquiry as the model for all enquiry and to apply scientific thinking and scientific method in areas where they are not appropriate. That is the point we explored in 1.i. And that fundamental point is not affected by the adoption of a more realistic picture of scientific practice, which recognizes the pluralism of actual scientific practice and acknowledges that science need not be either reductionist or essentialist. Consider Wittgenstein's opposition to the scientism of Frazer's anthropology. His central criticisms are that Frazer proceeds by searching for causal explanations of the practices he studies, and that he treats those practices themselves as manifestations of a kind of primitive causal understanding of the world. What makes Frazer's anthropology scientistic is its application of scientific, causal explanatory, thinking in areas where such thinking is 
W. Child - "Wittgenstein, Scientism \& Anti-Scientism in the Philosophy of Mind" - in Wittgenstein and Scientism, eds. Jon Beale and Ian James Kidd, London: Routledge, pp. 81-100.

inappropriate: first, in its own practice; and second, in its conception of its objects of study. That point retains its force once we have corrected the misrepresentations in some of Wittgenstein's remarks about science.

Second, as we have seen, much of Wittgenstein’s criticism is directed not at scientific enquiry itself but at the scientistic 'spirit of the main current of European and American civilization'. To that extent, what matters for Wittgenstein's critique is not the nature of science as it is actually practised but rather the dominant perception of science: for it is the perception of science, rather than the actual nature of scientific practice itself, that informs the spirit of our civilization. And it is very plausible that the dominant perception does involve a naïve and simplistic image of science: an image that incorporates, amongst other things, the kind of reductionism and essentialism that Wittgenstein describes. (Indeed, it is arguable that part of the scientism of contemporary civilization is precisely its tendency to idealize science in a way that distorts the reality of scientific practice. ${ }^{6}$ ) So Wittgenstein can be right that the scientism of modern civilization includes a tendency to reductionism and essentialism, even if those tendencies have little place in science itself.

In subsequent sections, we will encounter other cases in which comments of Wittgenstein's arguably misrepresent the character of actual scientific practice (see 3.i and 3.ii below). It is hard to resist the thought that his hostility to the scientism of modern culture sometimes leads him to paint a false picture of science itself. But, for the reasons just discussed, the lack of charity in some of his remarks does not for the most part alter the force of the anti-scientistic points he is making.

\section{Anti-scientism and philosophy of mind}

In his 'Remarks on Frazer's Golden Bough', we saw, Wittgenstein opposes two kinds of scientism in anthropology: the scientism of doing anthropology as though it is a science; and the scientism of treating magical beliefs as a primitive form of science. In a similar way, Wittgenstein opposes two kinds of scientism in philosophy of mind: the scientism of doing philosophy of mind as though it is a science; and the scientism of treating common-sense psychology as though it is a primitive form of science. We can take these points in order.

2.i In a well-known warning against scientism in philosophy, Wittgenstein writes: Philosophers constantly see the method of science before their eyes and are irresistibly tempted to ask and answer questions in the way science does. This tendency is the real source of metaphysics, and leads the philosopher into complete darkness. I want to say here that it can never be our job to reduce anything to anything, or to explain anything. (BB 18)

But how must we proceed in philosophy - and in philosophy of mind in particular - if we are to avoid the scientism of 'asking and answering questions in the way science does'? Wittgenstein's prescription seems clear. We must reject any kind of reduction of mental phenomena to phenomena of some other kind. We must reject the essentialist assumption that phenomena of a given mental kind are always united by sets of common defining features. Above all, we must avoid treating our philosophical problems as if they were scientific ones. I will focus on this last point.

A scientific problem, according to Wittgenstein, arises where we are ignorant of factual truths about the natural world. It is solved by discovering new facts: a causal explanation; a natural law; the internal constitution of a kind of stuff. A philosophical problem is quite different; it is 'a muddle felt as a problem' (BB 6). The characteristic of a philosophical question, Wittgenstein says, is 'that we express an unclarity about the grammar of words in the form of a scientific question' (BB 35). ${ }^{7}$ But dealing with a philosophical 
W. Child - "Wittgenstein, Scientism \& Anti-Scientism in the Philosophy of Mind" - in Wittgenstein and Scientism, eds. Jon Beale and Ian James Kidd, London: Routledge, pp. 81-100.

question does not require discovering new facts or causal explanations. Rather, it requires unravelling the 'muddle' that led to the feeling that there was a problem in the first place. In Wittgenstein's view, then, philosophy of mind is scientistic when it treats its questions as empirical questions and seeks to answer them with empirical information. To avoid scientism, we must recognize that philosophical questions are not empirical questions, we must understand that they are not solved by empirical discoveries or causal explanations, and we must trace those problems to their source in muddles that are 'brought about, among other things, by certain analogies between the forms of expression in different regions of our language' (PI §90). We can consider two examples of this anti-scientistic approach in Wittgenstein's philosophy of mind.

The first comes from Wittgenstein's discussion of the phenomenon of seeing an aspect: seeing an ambiguous figure as a picture-duck or a picture-rabbit; seeing a likeness between two faces; and so on (see PPF xi (PI II xi)). A constant refrain in that discussion is the question, whether seeing an aspect is a kind of seeing or a kind of thinking: whether it is an experiential phenomenon or a cognitive phenomenon. 'Was it seeing, or was it a thought?' (PPF §187 (PI II xi 204d)); 'Is it a genuine visual experience?’ (PPF §190 (PI II xi 204g)); 'Do I really see something different each time, or do I only interpret what I see in a different way?’ (PPF §248 (PI II xi 212d))? ${ }^{8}$ The scientistic philosopher of mind treats that as a straightforwardly factual question, to be resolved by empirical investigation. That is the way of thinking that underpins the common suggestion that the question, whether or not seeing an aspect is a genuinely experiential phenomenon, has to be settled by physiological investigation. But Wittgenstein thinks that is a fundamental mistake. Information about what goes on physiologically when someone sees an aspect is interesting in itself. But to appeal to that physiological information to settle the question, whether seeing an aspect is a kind of seeing, is to change the subject: it 'introduce[s] a new, a physiological, criterion for seeing' (PPF §236 (PI II xi 212c)). And that leaves our original question untouched. The original question was not, what is going on in a person's brain when she sees an aspect, but rather whether - or to what extent - the phenomenon falls under the existing concept of seeing. And, according to Wittgenstein, that question can only be addressed at the level of our ordinary psychological concepts, not by shifting to a different set of concepts and a different level of description. (There is no space here for a critical discussion of the assumptions implicit in Wittgenstein's view of the matter: in particular, his assumptions about the relation between physiological and psychological concepts and levels of description. But it is important to acknowledge the centrality of those assumptions in his objections to scientism in philosophy of mind.)

A second example is Wittgenstein's treatment of the question, how it is possible to know that someone else is in pain. The scientistic philosopher treats this as an empirical issue, to be addressed by exploring the causal mechanisms that allow one person to track another person's states of pain. But in Wittgenstein's view, that fails to recognize or respond to the source and nature of the original question. In ordinary life, we don't think there is any difficulty in one person's knowing that another is in pain. But when we reflect philosophically, we easily get into a frame of mind in which it seems in principle impossible for one person to know whether another is in pain. A philosophical treatment of the question, Wittgenstein insists, must identify the source of that idea and show us how to avoid it. But the scientistic approach does nothing to address that sense of puzzlement; it simply ignores it. Wittgenstein's own response to the problem is quite different. According to Wittgenstein, the idea that I can never really know that someone else is in pain is prompted by the following way of thinking. The other person knows that she has toothache because she feels her toothache; but I cannot feel her sensation; so I can never really know whether she has toothache. On that way of thinking, the case of other minds is analogous to a case like this. 
W. Child - "Wittgenstein, Scientism \& Anti-Scientism in the Philosophy of Mind" - in Wittgenstein and Scientism, eds. Jon Beale and Ian James Kidd, London: Routledge, pp. 81-100.

To know whether she has a gold tooth, I need to see inside her mouth; but I cannot see inside her mouth; so I do not know whether she has a gold tooth. ${ }^{9}$ But, Wittgenstein argues, the two cases are not analogous at all. It is true that I cannot feel someone else's toothache. But the reason is a conceptual or grammatical one. Any toothache I feel is my toothache, by virtue of the fact that it is me who is feeling it. So there is no such thing as feeling someone else's toothache. But in that case, the fact that I cannot feel someone else's toothache does not mean that there is some deficiency in my evidence about her sensations; it simply reflects the fact that the person with toothache is someone else, not me. So the reasoning that led us to think that I can never know whether someone else has toothache was a mistake: it involved a 'muddle' - a false analogy between different cases. Once we recognize that, we can see that nothing stands in the way of accepting the common-sense thought that one person can know that another is in pain. 'If I see someone writhing in pain with evident cause, I do not think: all the same, his feelings are hidden from me' (PI II xi p. 223). And I am obviously right not to think that. In such a case - as in many others - I can know perfectly well what someone else is feeling, on the basis of what he says and does. That is a good illustration of Wittgenstein's approach to questions in the philosophy of mind, and of how it contrasts with the way the scientistic philosopher approaches those questions. ${ }^{10}$

2.ii We turn now to Wittgenstein's opposition to a second kind of scientism he finds in much philosophy of mind: the scientism of treating common-sense psychology as if it were a kind of science - a theory of the causal mechanisms that produce behaviour. That conception of common-sense psychology comes in two versions: there is the idea that common-sense psychology is a theory about the internal, physical causes of behaviour; and there is the more nebulous image of common-sense psychology as a theory about a 'mental mechanism' that produces behaviour - a mechanism whose nature is left unspecified, but which we are tempted to picture as 'gaseous' or 'aethereal' (see BB 47). Opposition to that way of thinking is central to Wittgenstein's rejection of what he calls the 'inner-outer picture': the picture of sensations and thoughts as internal, mental phenomena that lie behind the outer surface of people's behaviour.

Wittgenstein's rejection of this 'inner mechanism' view is fundamental to his own conception of common-sense psychology. He takes it to be obvious that, in talking of people's thoughts, intentions, sensations and so on we are not talking about features of an inner mechanism: phenomena going on in an inner realm, hidden behind people's behaviour. Common-sense psychology, he thinks, is an autonomous scheme of description and explanation that we employ in talking of ourselves and others. The terms it uses - 'pain', 'irritation', 'intention', 'belief', and so on - are defined by their places within that scheme. And it is not a condition for the truth of common-sense psychological ascriptions that there should be any particular pattern of correlations between the states and episodes they ascribe and the literally internal states and episodes described by neurophysiology and other sciences. The ordinary practice of applying mental terms to ourselves and others, he thinks, carries no commitment to the idea that we are talking about states and events that are literally internal. But when we step back from the ordinary practice and think reflectively about it, the 'picture of the inner and the outer' (LW II 28) naturally suggests itself. For the inner-outer picture seems to explain some of the distinctive features of common-sense psychology: the asymmetries between first-person and second-and-third-person mental ascriptions, for instance; and the 'uncertainty' or 'indeterminacy' of the relation between behavioural evidence and the mental states we ascribe to others on the basis of that evidence. ${ }^{11}$ But, Wittgenstein insists, it is a mistake to think that common-sense psychology describes an inner mechanism that produces behaviour. 
W. Child - "Wittgenstein, Scientism \& Anti-Scientism in the Philosophy of Mind" - in Wittgenstein and Scientism, eds. Jon Beale and Ian James Kidd, London: Routledge, pp. 81-100.

If I say 'I can’t figure him out', this bears little resemblance to: 'I can’t figure this mechanism out.' I think it means approximately: I can't foresee his behaviour with the same certainty as with people 'with whom I do know my way about'. (LW II 65) ${ }^{12}$ The inner-mechanism idea, he thinks, is not built into common-sense psychology itself; it is simply a way in which we picture or interpret common-sense psychology.

You look at a face and say 'I wonder what's going on behind that face?' - But you don't have to say that. The external does not have to be seen as a façade behind Or again: which the mental powers are at work. (LW I 978)

The expression 'Who knows what is going on inside him!' The interpretation of outer events as consequences of unknown, or merely surmised, inner ones. The interest that is focused on the inner, as if on the chemical structure, from which behaviour issues.

For one needs only to ask, 'What do I care about inner events, whatever they are?!', to see that a different attitude is conceivable. - 'But surely everyone will always be interested in his inner life!' Nonsense. Would I know that pain, etc., etc. is something inner if I weren't told so? (RPP II 643 (translation adjusted))

Wittgenstein, then, rejects the idea that common-sense psychology is to be understood as a primitive science of the internal causes of behaviour. That idea, he thinks, is a manifestation of the scientistic tendency to treat all description and explanation on the model of scientific description and explanation. That way of understanding common-sense psychology is pervasive in much contemporary philosophy of mind. ${ }^{13}$ But there is also a prominent dissenting tradition, which sides with Wittgenstein's insistence that we should not understand common-sense psychology as a rudimentary science of the internal causes of behaviour but should treat it, rather, as an autonomous system of description and explanation, governed by its own norms. ${ }^{14}$

\section{Anti-scientism and the 'uncertainty' of the relation between the 'outer' and the}

\section{'inner'}

The general lines of Wittgenstein's anti-scientism in philosophy of mind - which I have sketched in the previous section - are relatively familiar. Less often discussed is the particular way in which some of those lines are drawn out in the late notebooks published as Last Writings on the Philosophy of Psychology: Volume II. I comment here on some important themes.

As Wittgenstein insists, we often know what someone else is feeling. But in many other cases we do not know what others are feeling. Is she really glad to see me; or is she simply pretending to be glad? Is she really irritated? Is she really in pain? And so forth. The uncertainty of the judgements we make about others' feelings on the basis of their circumstances and behaviour, Wittgenstein thinks, is 'an (essential) trait' of the 'languagegame' of ascribing feelings to ourselves and others (LW I 877). How should we understand that uncertainty?

3.i It is tempting, Wittgenstein says, to think that the uncertainty of judgements about other people's feelings and attitudes is a purely epistemic matter. We may not know whether or not someone is irritated. But, it is tempting to assume, there is definite fact of the matter: either she is irritated or she is not irritated. Likewise, her behaviour may leave us uncertain whether or not she is really glad to see me, whether or not she is really in pain, and so on. But there is always a determinate fact of the matter: either she is glad to see me or she is not glad to see me; either she is in pain or she is not in pain; etc.. Wittgenstein puts that tempting view like this: 
W. Child - "Wittgenstein, Scientism \& Anti-Scientism in the Philosophy of Mind" - in Wittgenstein and Scientism, eds. Jon Beale and Ian James Kidd, London: Routledge, pp. 81-100.

[we imagine] the experience (the pain, for instance) as a thing, for which of course we have a name and whose concept is therefore quite easy to grasp.

So we always want to say: We know what 'pain' means (namely this), and so the difficulty only consists in simply not being able to determine this in someone else with certainty. (LW II 43)

But, he thinks, that way of seeing things involves a kind of scientism about the 'inner'. It exemplifies an attitude that Wittgenstein ascribes to scientists: 'We still don't know that; but it is knowable and it is only a matter of time before we get to know it!' (CV 40). Against that view, Wittgenstein argues that uncertainty about another's feelings or mental states is not always an epistemic matter; there is also a constitutional uncertainty or indeterminacy. ${ }^{15}$ The question, 'Is she really irritated?', expects a definite answer: yes or no. But, Wittgenstein insists, there need be no determinate fact to the effect either that she is irritated or that she is not irritated. As he puts it:

it is misleading to think of the real irritation as a facial expression of an inner face, so to speak, such that this facial expression is defined completely clearly, and that it is only the outer face that makes it uncertain whether the soul really has this expression. (LW II 70)

Of course, amongst cases where the behavioural evidence leaves us uncertain whether someone is irritated or not, there are some cases where the person is in fact definitely irritated, and others where she is definitely not irritated. But, Wittgenstein insists, there are other cases where there is no determinate fact of the matter.

Wittgenstein is plainly right to reject the kind of scientism about the mental that treats the uncertainty of the relation between outer evidence and inner state as always being a merely epistemic matter. And he is right to reject the assumption that there is always a determinate fact of the matter to the effect either that a person has a given feeling or that she does not. As before, however, we might wonder how close a connection there is between that kind of scientism and actual science. Scientists do not typically ignore the possibility that the phenomena they investigate may not be determinately characterizable with their existing concepts. Indeed, the idea of constitutional indeterminacy is a famously central theme in modern physics. So if Wittgenstein were seriously accusing actual scientists of treating all uncertainty as a purely epistemic matter and ignoring the existence of constitutional uncertainty or indeterminacy, he would be guilty of a naïve or scientistic view of science itself. In defence of Wittgenstein, we can repeat the point made in 1.iv above: to the extent that his criticism is directed in the first instance at the scientism that is characteristic of 'the spirit of the main current of European and American civilization' (CV 6), he could reasonably say that his comments are directed at our culture's pervasive image of science, whilst acknowledging that the pervasive image misrepresents the way science actually works. Nonetheless, it is hard to avoid the suspicion that some of Wittgenstein's comments do betray an inaccurate understanding of the enterprise of science as it actually exists, and an uncharitable view of scientists' actual thinking.

3.ii In his late writings on philosophy of psychology, Wittgenstein reflects at length on the character of the relation between outer evidence and the inner states we ascribe on the basis of that evidence. He comments specifically on ways in which it differs from the relation between evidence and what it is evidence for in science. Some key points from that discussion are the following:

- A claim to know what someone else is feeling is different in character from a physicist's claim to know the outcome of a particular experiment or a mathematician's claim to know the outcome of a calculation (LW II 88). Statements about others' feelings are inherently contestable or open to doubt in a way that 
W. Child - "Wittgenstein, Scientism \& Anti-Scientism in the Philosophy of Mind" - in Wittgenstein and Scientism, eds. Jon Beale and Ian James Kidd, London: Routledge, pp. 81-100.

statements about simple observations in physics or about the outcomes of calculations in mathematics are not.

- Relatedly, one can know on the basis of evidence that someone else is genuinely glad, say, without being able to give reasons that will convince a third party of the correctness of one's judgement (LW II 86).

- Mental states, or 'inner conditions', have characteristic observable consequences. But these 'characteristic consequences' 'cannot be described in the same way as the reactions that characterize the state of a physical object' (LW II 90); 'One can't formulate them in general terms' (PPF §357 (PI II xi 228a)); and they cannot be exactly systematized or predicted.

- Similarly, there are no 'exact rules of evidence' for ascribing inner states to a person on the basis of what she says and does (LW II 94). By contrast, Wittgenstein implies, there are exact rules of evidence in other fields of enquiry.

- There is no general 'technique' for judging whether an expression of feeling is genuine or not. And, though there are rules for making such judgements, they are only rules of thumb: they 'do not form a system . . . Unlike calculating rules' (PPF $\S 355$ (PI II xi 227h)).

- The evidence that someone is in such-and-such a state of mind includes 'imponderable' evidence: evidence that has no systematic or quantifiable relation with what it is evidence for (PPF §358 (PI II xi 228b)). ${ }^{16}$

Putting those points together, Wittgenstein's discussion suggests the following view. 'In science, there are exact rules of evidence: the relation between a given state and the effects on the basis of which we detect the presence of that state is governed by precise, quantitative laws; there are definite techniques or procedures for determining with certainty the presence or absence of such states. Ascribing experiences and inner states to people on the basis of their circumstances and behaviour is fundamentally different in each of those respects; it is in the nature of the mental that there can be no exact, codifiable relation between inner states and outer circumstances and behaviour.' So Wittgenstein takes there to be a fundamental contrast between common-sense psychology and science. I want to explore two objections to that claim.

A first objection is that Wittgenstein's contrast depends once more on a crude and scientistic view of science. We can put the point like this. 'Wittgenstein may be right about the nature of common-sense psychology. But, once more, the actual practice of the sciences does not fit the picture of science he offers. In particular, evidential support in science does not work in the exact, systematic, rule-governed way that Wittgenstein suggests. ${ }^{17}$ That is a good point. But it is not fatal to the contrast that Wittgenstein is drawing. In the first place, it is plausible that, when Wittgenstein talks of 'exact rules of evidence', or the systematic description of the 'reactions that characterize the state of a physical object', he is thinking of what Kuhn would call 'normal science' rather than 'revolutionary science'. ${ }^{18}$ He would surely agree that things are different when we are in the situation of judging between competing theoretical paradigms in science. Judgements of that kind, he could acknowledge, are in important respects much more like judgements about another person's inner states; there is no technique for making such judgements - no system of exact rules. Contrast the case where we are smoothly applying an established theory: using established laws in physics or chemistry, say, to predict or explain particular phenomena. In that case, he might say, the contrast between common-sense psychology and the physical sciences is just as he describes it.

The critic may object that, even when restricted to 'normal science', Wittgenstein's characterization of the relation between evidence and what it is evidence for in science does not fit actual scientific practice. The physical sciences do indeed formulate exact, 
W. Child - "Wittgenstein, Scientism \& Anti-Scientism in the Philosophy of Mind" - in Wittgenstein and Scientism, eds. Jon Beale and Ian James Kidd, London: Routledge, pp. 81-100.

quantitative laws. But even in the physical sciences, there are no exact rules of evidence. The interpretation of data always leaves room for alternative hypotheses and confirmation is never a merely algorithmic process. And in the biological sciences, Wittgenstein's picture of exact, quantitative rules of evidence is even further removed from the facts of actual scientific practice. As before, the point is well taken, but Wittgenstein's contrast remains defensible. For one thing, even if there are no exact rules of evidence in science the assessment of evidence remains subject to an ideal of exactness; but, Wittgenstein insists, that ideal has no place in common-sense psychology. Relatedly, even if the assessment of evidence in science is ineliminably inexact, the underlying phenomena that science investigates are governed by exact, quantitative laws. By contrast, there are no exact laws governing the relations between attitudes, experiences, and behaviour.

A second objection to Wittgenstein's contrast between common-sense psychology and science is this. 'Suppose we think of mental states, contra Wittgenstein, as states of an inner mechanism that produces behaviour. A person's observable behaviour is on this view the upshot of causal interactions amongst a vast network of mental states. Since the network is extremely complex it is no surprise that the occurrence of a particular bit of behaviour does not give us conclusive evidence for the presence of a specific inner state. Contrast a simple case in physical science: say, the evidence provided by the reading on an ammeter for the presence in a wire of a current of given magnitude. In a case like that, there really are "exact rules of evidence". But science does not deal only with simple cases of that sort; it also deals with highly complex systems. And with complex physical systems, we find exactly the same absence of exact, quantitative rules to which Wittgenstein draws attention in the mental case. Consider weather-forecasting. The weather at a particular time and place is the result of a huge range of factors that causally interact with one another in complex, even chaotic, ways. Because of that, the relation between the observable evidence (atmospheric pressure, wind speed, humidity, today's weather, etc.) and what it is evidence for (tomorrow's or next week's weather) is inexact and in practice impossible to quantify; correspondingly, uncertainty attaches to any forecast of the weather. In the same way, the complexity of the system of inner states that produces behaviour means that the relation between behavioural evidence and what it is evidence for (a particular thought, or experience, or mental state) is inevitably inexact and unquantifiable; and ascriptions of mental states are similarly uncertain. In both cases, the uncertainty of the relation between evidence and what it is evidence for is explained by the complexity of the causal factors involved. And in both cases, the uncertainty is in principle resolvable: as we learn more about the details of the complex system that produces the weather, and as we are better able to handle the computational complexity required to model it, we come ever closer to a system of exact rules of evidence for weather-forecasting. Similarly, as we learn more about the complex mechanism that produces behaviour, we come ever closer to a system of exact rules of evidence for ascribing mental states on the basis of the behaviour that they produce. So Wittgenstein is wrong: the uncertainty of common-sense psychology does not point to any principled difference between common-sense psychology and science.’

Wittgenstein would respond that this way of making sense of the uncertainty of the relation between a person's behaviour and their mental states gets things back to front.

It is not the relationship of the inner to the outer that explains the uncertainty of the evidence, but rather the other way around - this relationship is only a picture-like representation of this uncertainty. (LW II 68)

Wittgenstein's point is this. The suggestion sketched in the previous paragraph is precisely that 'the relation of the inner to the outer . . . explains the uncertainty of the evidence'; the complexity of the way in which behaviour is generated from the interactions of multiple mental states explains why there are no exact, quantitative rules for getting from observations 
W. Child - "Wittgenstein, Scientism \& Anti-Scientism in the Philosophy of Mind" - in Wittgenstein and Scientism, eds. Jon Beale and Ian James Kidd, London: Routledge, pp. 81-100.

of behaviour to ascriptions of mental states. Wittgenstein takes a different view. The uncertainty of the evidential relation between behaviour, on the one hand, and experiences and mental states, on the other, is a primitive feature of the scheme. That is to say: the fact that there are no exact, quantitative rules for attributing mental states on the basis of behaviour is not the upshot of something else; it is just a primitive feature of the commonsense psychological scheme. As philosophers, we feel that the lack of exact rules of evidence in common-sense psychology must be explicable; it must result from some further, independent fact about the mental. And the idea of the mental as an inner, behaviourproducing mechanism seems to point to such an explanation: the reason there are no exact rules of evidence is that the states of the mechanism are related to behaviour in ways too complex to systematize or quantify. But, Wittgenstein insists, the explanation is illusory. The inner-mechanism view of the mind, he holds, is no more than a picture: a way of representing the uncertainty of the relation between behaviour and the mental. It does not explain the uncertainty; it simply restates it.

I said earlier that the idea of the mind as an inner mechanism comes in two versions. In one version, the inner is conceived as a physical mechanism: the brain and nervous system. In another version, it is conceived as a mental mechanism: something immaterial or aethereal. Wittgenstein's critic may concede that the defence outlined in the previous paragraph is effective against the mentalist version of the inner-mechanism view. The idea that our words and actions are produced by an aethereal, mental mechanism is indeed a mere picture with no real substance: a projection onto reality of the structure of our mental vocabulary. But, she will say, things are different with the physicalist version of the view. For it is obviously not an illusion that we have brains and nervous systems, or that they are responsible for producing the movements of our bodies. So how can it be wrong to trace the uncertainty of the relation between mental states and behaviour to the complexity of the physical mechanism that causes our behaviour?

Wittgenstein's response would be, as before, to draw a sharp distinction between facts about people's thoughts, experiences, intentions etc. and facts about their brains and nervous systems. The uncertainty we wanted to understand was the uncertainty of the relation between behaviour and mental states. To talk about the complexity of the relation between behaviour and internal physical states, he thinks, is to change the subject; it cannot explain the relation between mental states and behaviour. That is the move he makes in a discussion in Last Writings on Philosophy of Psychology, volume II, where he imagines having complete knowledge of the nervous system. It is tempting, he says, to think that complete knowledge of the nervous system would give us a way of resolving questions about the mental that we cannot resolve with our ordinary methods: the question whether someone is really in pain or not, for instance.

If a way of seeing his nerves working were now found, wouldn't that really be a means of finding whether he is in pain? ... And could you ask for more than to see the workings of the nervous system? (LW II, 31)

But Wittgenstein rejects that tempting thought:

If as I was assuming people really could see someone else's nervous system working, and adjust their behaviour toward him accordingly, then, I believe, they wouldn't have our concept of pain (for instance) at all, although maybe a related one. Their life would simply look quite different from ours. (LW II 40)

A concept whose application was directly answerable to facts about people's nervous systems rather than to facts about their behaviour and circumstances, he thinks, would simply be a different concept from our concept pain. If we could see the working of people's nervous systems and apply the term 'pain' in the light of that, we would not be achieving greater 
W. Child - "Wittgenstein, Scientism \& Anti-Scientism in the Philosophy of Mind" - in Wittgenstein and Scientism, eds. Jon Beale and Ian James Kidd, London: Routledge, pp. 81-100.

accuracy in our ascriptions of pain; we would be changing the subject - using the term 'pain' to talk about something other than pain.

Many philosophers of mind would disagree. They take it as obvious that, in making these discoveries about the nervous system, we would be discovering the nature of pain. And they take it as obvious that information about the nervous system would resolve questions about the presence or absence of pain that cannot be answered in our ordinary ways. But in Wittgenstein's view, those ideas are another manifestation of scientism in philosophy of mind. His opponents' underlying assumption, he thinks, is that science has a monopoly on the truth. It is that assumption that drives the idea that, if our ordinary mental terms pick out anything at all, the properties they pick out must be properties that are identified by the sciences of the nervous system. Against that, Wittgenstein insists that it is a scientistic error to think of every kind of description and every kind of explanation on the model of scientific description and explanation. As I have tried to show, Wittgenstein's anti-scientism about the mental has many facets. But one of its central messages is this; we should not construe common-sense psychology as a rudimentary science of the internal causes of behaviour - in either the mentalist or the physicalist version of that view. ${ }^{19}$ 
W. Child - "Wittgenstein, Scientism \& Anti-Scientism in the Philosophy of Mind" - in Wittgenstein and Scientism, eds. Jon Beale and Ian James Kidd, London: Routledge, pp. 81-100.

\section{Bibliography}

Works by Wittgenstein

BB The Blue and Brown Books, 2nd edition, Oxford: Blackwell, 1969.

CV Culture and Value, 2nd edition, ed. G. H. von Wright and H. Nyman, trans. P. Winch, Oxford: Blackwell, 1978

LW I Last Writings on the Philosophy of Psychology Volume I, eds. G. H. von Wright and H. Nyman, trans. C. Luckhardt and M. Aue, Oxford: Blackwell, 1982.

LW II Last Writings on the Philosophy of Psychology Volume II, eds. G. H. von Wright and H. Nyman, trans. C. Luckhardt and M. Aue, Oxford: Blackwell, 1992.

PI Philosophical Investigations, 4th edition, eds. P. M. S. Hacker and J. Schulte, trans. G. E. M. Anscombe, P. M. S. Hacker, and J. Schulte, Oxford: Blackwell, 2009.

RFGB 'Remarks on Frazer's Golden Bough', in Wittgenstein, Philosophical Occasions 1912-1951, eds. J. Klagge and A. Nordmann, Indianapolis: Hackett Publishing Company, 1993.

PPF 'Philosophy of Psychology - A Fragment', in Wittgenstein, Philosophical Investigations, 4th edition. (This material appears in earlier editions as Philosophical Investigations part II. I give references in both forms: by numbered §’s in PPF; and by the page number and paragraph used in the 1st and 2nd editions of PI part II.)

PR Philosophical Remarks, ed. R. Rhees, trans. R. Hargreaves \& R. White, Oxford: Blackwell, 1975.

RPP II Remarks on the Philosophy of Psychology Volume II, eds. G. H. von Wright and H. Nyman, trans. C. Luckhardt and M. Aue, Oxford: Blackwell, 1980.

Z Zettel, 2nd edition, eds. G. E. M. Anscombe and G. H. von Wright, trans. G. E. M. Anscombe, Oxford: Blackwell, 1981.

Other works

Burley, M. (2012) 'Wittgenstein, Wonder and Attention to Animals', in N. Forsberg, M.

Burley, and N. Hämäläinen (eds) Language, Ethics and Animal Life: Wittgenstein and Beyond, London: Bloomsbury.

Cartwright, N. (1999) The Dappled World: A Study of the Boundaries of Science, Cambridge: Cambridge University Press.

Child, W. (2011) Wittgenstein, London: Routledge.

Child, W. (2017) 'Wittgenstein on Inner-Outer and Avowals', in H.-J. Glock and J. Hyman (eds) The Blackwell Companion to Wittgenstein, Oxford: Wiley-Blackwell.

Churchland, P. (1981) 'Eliminative Materialism and the Propositional Attitudes', Journal of Philosophy 78: 67-90.

Davidson, D. (1980) Essays on Actions and Events, Oxford: Oxford University Press.

Dennett, D. (1971) 'Intentional Systems', Journal of Philosophy 68: 87-106.

Dennett, D. (1987) 'Three Kinds of Intentional Psychology', in D. Dennett The Intentional Stance, Cambridge, MA: MIT Press.

Dupré, J. (1993) The Disorder of Things: Metaphysical foundations of the disunity of science, Cambridge: MA: Harvard University Press.

Feyerabend, P. (1978) Against Method, London: Verso.

Fodor, J. (1975) The Language of Thought, Hassocks: Harvester.

Frazer, J. (1994) The Golden Bough: A Study in Magic and Religion, new abridged edition, ed. R. Fraser, Oxford: Oxford University Press. (Third edition first published in twelve volumes, London: Macmillan, 1906-15.)

Kidd, I. J. (2017) 'Reawakening to Wonder: Wittgenstein, Feyerabend, and Scientism', in J. Beale and I. J. Kidd (eds) Wittgenstein and Scientism, London: Routledge. 
W. Child - "Wittgenstein, Scientism \& Anti-Scientism in the Philosophy of Mind" - in Wittgenstein and Scientism, eds. Jon Beale and Ian James Kidd, London: Routledge, pp. 81-100.

Kuhn, T. (1970) The Structure of Scientific Revolutions, 2nd edition, Chicago: University of Chicago Press.

Malcolm, N. (1984) Ludwig Wittgenstein: A Memoir, 2nd edition, Oxford: Oxford University Press.

Williams, B. (1973) 'Wittgenstein and Idealism’, Royal Institute of Philosophy Lectures, 7: 76-95. 
W. Child - "Wittgenstein, Scientism \& Anti-Scientism in the Philosophy of Mind" - in Wittgenstein and Scientism, eds. Jon Beale and Ian James Kidd, London: Routledge, pp. 81-100.

\section{Notes}

1 See e.g. BB 5-6, where Wittgenstein says that a scientific problem is one where there are 'effects which we [are] not yet able to explain (causally)'; and BB 88, where he says that 'the task of the experimental sciences' is to test causal hypotheses.

2 See, for instance, Cartwright 1999, Dupré 1993, Feyerabend 1978, and Kuhn 1970.

3 See Frazer's discussion of the Beltane festival in Frazer 1994, 716 ff.

${ }^{4}$ For a more detailed treatment of Wittgenstein's discussion of Frazer and anthropology, see Child 2011: 229-39.

${ }^{5}$ For some of Wittgenstein's views about academic philosophy, see the letters to Norman Malcolm reproduced in Malcolm 1984, 88-89.

6 See Kidd 2017 for a development of this theme.

${ }^{7}$ What Wittgenstein actually says in BB 35 is something more specific: that this is characteristic of 'a metaphysical question'. But I think he would accept the extension of the point from metaphysical questions to philosophical questions in general.

${ }^{8}$ For other instances of the same kind of question, see PPF $\S \S 141,144,149,171,172,183$, 185, 206. (PI II xi pp. 197e, 197h, 198e, 201g, 202b, 203e, 204b, 206f.)

${ }^{9}$ For this analogy, see BB 49.

${ }^{10}$ For an interesting exploration of our relation to the mental lives of animals, which draws on Wittgenstein's discussion of the topic and emphasizes the role of his anti-scientism, see Burley 2012.

${ }^{11}$ For more on Wittgenstein's view of the genesis of 'the inner-outer picture', see Child 2017.

12 Later passages in LW II make it clear that Wittgenstein thinks the positive characterization he offers here is too crude. But he remains convinced by the negative point.

13 Two influential proponents of this view are Paul Churchland (e.g. Churchland 1981) and Jerry Fodor (e.g. Fodor 1975).

${ }^{14}$ Prominent representatives of this dissenting tradition include Donald Davidson (e.g. Davidson 1980, essays 11-13) and Daniel Dennett (e.g. Dennett 1971 and Dennett 1987).

15 For the notion of 'constitutional uncertainty' in the relation between outer evidence and inner state, see RPP II 657.

${ }^{16}$ We can note in passing the clear echoes of these Wittgensteinian ideas in Davidson's philosophy of mind.

17 For this point, see again the works cited in note 2.

18 For this distinction, see Kuhn 1970.

19 An earlier version of this paper was presented to the Workshop on Wittgenstein and Scientism at the University of Durham in July 2012. I am grateful to the organizers and participants for discussion on that occasion, and to Ian James Kidd for particularly helpful written comments. Thanks are due to the Arts and Humanities Research Council for the award of a Research Fellowship that supported the research for this paper. 